man-to-human spread. Whether human-to-human transmission occurred is a scientific judgment.

We agree with Uyeki and Bresee that statistical modeling can provide useful and supportive insights, and we hope that epidemiologic teams who investigate and control potential infectious disease outbreaks will carry the TranStat software (2) into the field with them. We are grateful that Uyeki and Bresee point out that immediate implementation of containment measures is critical, even while we sort out the cause of an observed cluster of cases. Actually containing possible spread of a potential pandemic strain of influenza $(4,5)$ is more important than scientific arguments about the transmissibility of the infectious agent in question.

Ira M. Longini, Jr., ${ }^{*}+$ Yang Yang, ${ }^{*}$ Jonathan Sugimoto, ${ }^{*} \dagger$ and M. Elizabeth Halloran*†

*Fred Hutchinson Cancer Research Center, Seattle, Washington, USA; and +University of Washington, Seattle, Washington, USA

\section{References}

1. Uyeki TM, Bresee JS. Detecting humanto-human transmission of avian influenza A (H5N1) [letter]. Emerg Infect Dis. 2007:13:1969-70.

2. Yang Y, Halloran ME, Sugimoto J, Longini IM Jr. Detecting human-to-human transmission of avian influenza A (H5N1). Emerg Infect Dis. 2007;13:1348-53.

3. Evans AS. Causation and disease: the Henle-Koch postulates revisited. Yale J Biol Med. 1976;49:175-95.

4. Longini IM, Nizam A, Xu S, Ungchusak K, Hanshaoworakul W, Cummings DA, et al. Containing pandemic influenza at the source. Science. 2005;309:1083-7.

5. Yang Y, Longini IM, Halloran ME. A resampling-based test to detect personto-person transmission of infectious disease. The Annals of Applied Statistics. 2007;1:211-28.

Address for correspondence: Ira M. Longini, Jr., Program in Biostatistics and Biomathematics, Fred Hutchinson Cancer Research Center, Seattle, WA98109-1024, USA; email: longini@ scharp.org

\title{
Swimming With A Hundred Year Old Snapping Turtle
}

\section{Freya Manfred}

I spy his head above the waves,

big as a man's fist, black eyes peering at me, until he dives into darker, deeper water.

Yesterday I saw him a foot from my outstretched hand, already tilting his great domed shell away.

Ribbons of green moss rippled behind him, growing along the ridge of his back and down his long reptilian tail.

He swims in everything he knows, and what he knows is never forgotten. Wisely, he fears me as if I were the Plague, which I am, sick unto death, swimming to heal myself in his primeval sea.

Published by RED DRAGONFLY PRESS, Northfield, Minnesota; email: kings@rconnect.com

\section{Announcing}

the 2008

International Conference on

Emerging Infectious Diseases

March $16-19,2008$

Hyatt Regency Atlanta

Atlanta, Georgia, USA

Late Breaker Abstract Submission

Deadline: February 1, 2008

\section{Www.ICEID.org}

Which infectious diseases are emerging?

Whom are they affecting?

Why are they emerging now?

What can we do to prevent and control them? 